\title{
Physical properties of commercial infant milk formula products
}

\author{
Murphy, E.G ${ }^{\mathrm{a}}$; Regost, N.E ${ }^{\mathrm{b}}$; Roos Y.H'; Fenelon M.A ${ }^{\mathrm{a}^{*}}$ \\ ${ }^{a}$ Teagasc Food Research Centre, Moorepark, Fermoy, Co. Cork, Ireland \\ ${ }^{b}$ Manager, Infant Formula Technologies, H\&H Group, Paris, France \\ 'School of Food and Nutritional Sciences, University College Cork, Cork, Ireland \\ *E-mail of the corresponding author: mark.fenelon@teagasc.ie
}

\begin{abstract}
The physical properties of 12 commercially available infant milk formula (IMF) and follow-on (FO) powders were assessed. Polarised light micrographs of powders revealed that two types of powders existed: Type Ihomogenous mixtures of milk powder particles and Type II - heterogeneous mixtures of milk powder particles and tomahawk-shaped $\alpha$-lactose monohydrate crystals. Conventionally employed correlations between particle size, flowability and compressibility were found to be highly dependent on the presence of crystalline lactose in powders. Overall, results showed the importance of micro-structural evaluation during analysis of physical properties of dairy powders and, in particular, IMF/FO powders.
\end{abstract}

Keywords: max. Infant formula; microstructure; physical properties. 


\section{Introduction}

Infant milk formula (IMF) powders are dehydrated emulsions consisting of the protein, fat carbohydrate, vitamins and minerals necessary to nourish infants in the absence of breast milk. Composition of powders changes as infants grow and IMF is classified into "stages" based on the age of the infants i.e. from birth, 6 months +, 1 year, follow on (FO), etc.. The U.S. Food and Drug Administration (2003) classify IMF manufacturing processes into three categories: 1) wet processing, 2) dry processing or 3) a combination of wet and dryblending. In wet processing, ingredients are hydrated in water to the desired composition and are subsequently spray dried [1]. Dry processing involves mixing of dried ingredients and is often employed in combination with spray dried base powder [2].

The manufacturing process has a large effect on the physical quality of dairy powders [1, 36]. Powder particle size can be controlled by viscosity of feed concentrate and agglomeration during spray drying $[7,8]$. Large powder particle sizes generally increase flowability due to a reduction in the area of contact between particles during flow [9]. However, other factors can affect flowability, which in some cases can lead to a weak relationship between particle size and flowability. The surface composition of powder particles is especially important in dehydrated emulsions and high quantities of nonemulsified fat at the powder surface can reduce flowability [10]. Shape of particles can also affect flowability of powders with more spherical powders having greater flowability [11]. $\alpha$-lactose monohydrate crystals are generally pyramidal or tomahawk shaped [12] and thus may reduce spherocity, and possibly, flowability of powders if present.

In recent years there has been an increase in the publications dealing with IMF manufacture [1, 5, 6, 13, 14]. Hanley et al. [13] provided some information regarding the physical properties of a limited number of commercial IMF samples, whereas the others did not equate data obtained to standard commercial products. This aim of this study were to determine differences in physical quality of commercial IMF related to composition of powders, microstructure and/or processes employed by manufacturers.

\section{Materials and Methods}

\subsection{Commercial infant milk formula}

A total of 12 IMF and FO powders were studied. 9 samples were purchased from an Irish supermarket and 3 samples of non-Irish IMF powders were donated by Biostime Inc. (Guangzhou, P.R. China). Crystalline structure of the powders was determined using polarised light microscopy (Olympus Corporation, Tokyo, Japan) and powders were subdivided into two categories; I - a homogenous mix of milk powder particles $(n=6)$ and II - a heterogeneous mix of milk powder particles and crystalline particles $(n=6)$. 


\subsection{Powder properties}

Particle size distribution was measured by a Mastersizer 3000 (Malvern Instruments Ltd., UK) as described elsewhere [14]. Sauter mean diameter, D[3,2], which gives the diameter of a sphere with the same volume to surface area ratio of the whole distribution was used as a measure of particle size. $\mathrm{D}(\mathrm{v}, 0.1)$, which gives the diameter below which $10 \%$ of the distribution (by volume) lies, was used to quantify the amount of fine particles in the distribution.

Particle shape was measured by Morphologi G3 (Malvern Instruments Ltd., UK). Powders were dispersed on to a microscope plate, using pressurised air. The air pressure used was 4 bar, which was applied to the sample dispersion for 10 milliseconds; a settling time of 1 minute was then allowed for powder particles to disperse on the microscope plate.

Bulk density and surface free fats were determined as per GEA Niro Standard [15]. The difference between poured and tapped (100 times) bulk densities gave the compressibility of the powder. Particle densities were measured by a helium gas pyconometer, AccuPyc II 1340 (Micromeritics, GA, USA).

\subsection{Flowability}

Flowability was measured by two methods: 1 - the time taken for a defined volume of powder to leave a rotating drum [15] and 2 - flow function measured using a Powder Flow Tester (Brookfield Engineering Laboratories Inc., MA, USA). For the drum flowability method it was noticed some powder would always adhere to the walls of the drum and would not exit. Therefore, the flowability from this method was defined as a flow-rate given by: $F_{d}=\left(g_{p 1}-g_{p 2}\right) / t i m e$, where $F_{d}$ is the drum flowability $(g / s)$; $g_{p 1}$ and $g_{p 2}$ represent the amount of powder ( $g$ ) in the drum at the start and finish of the test, respectively. Flow function was determined as described by Crowley et al. [16]. Five uniaxial normal stresses ( 0.3 to $2.4 \mathrm{kPa}$ ) were applied to each powder, in combination with three over-consolidation stresses at each normal stress. The Jenike flow index (i), was used to characterise the flow of the powders (Table 1; [11]).

Table 1. Jenike flow index (i) classification

\begin{tabular}{cccccc}
\hline Flowability & Hardened & Very cohesive & Cohesive & Easy-flow & Free-flowing \\
\hline i & $<1$ & $<2$ & $<4$ & $<10$ & $>10$ \\
\hline
\end{tabular}

\subsection{Statistical analysis}

A t-test was used to compare Type I and II powders.. Pearson's r was used to determine the degree of correlation between the two sample sets. This was calculated using the CORREL function of Microft Excel 


\section{Results and Discussion}

\subsection{Powder properties}

Polarised light microscopy revealed that standard IMF powders (made from intact bovine proteins) could be classified into two groups; I - homogenous powders and, II heterogeneous mixtures of non-crystalline particles and distinct crystalline particles (Figure 1). Type I powders showed small degrees of crystallinity indicated by bright areas within particles. This may be a result of partial lactose crystallisation which could occur, for example, if powder is not cooled sufficiently after spray drying or absorbs moisture locally during storage. The crystalline particles observed in Type II powders were very likely $\alpha$ lactose monohydrate due to their pyramidal or tomahawk shape [12]. The presence of crystalline lactose in Type II powders could indicate a manufacturing process where a base powder containing protein and fat ingredients was manufactured by spray drying, after which $\alpha$-lactose monohydrate crystals were added by dry-blending [2].

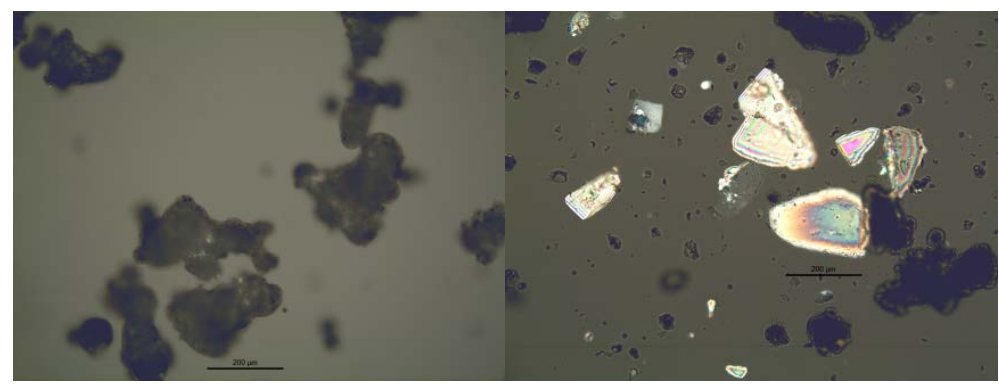

Figure 1. Polarised light images of Type I (powder 1) and II (powder 10) powders. Scale bar is 200 наm.

There were significant $(\mathrm{P}<0.05)$ differences in powder particle size and shape between Type I and II powders (Table 2). Type I powders had less fine particles $(\mathrm{D}(\mathrm{v}, 0.1))$, and as a result Sauter Mean Diameter, D[3,2], was significantly larger $(\mathrm{P}<0.05)$. D[3,2] gives the diameter of a sphere with the same volume to surface area ratio as the whole powder distribution [5]. The significantly larger D[3,2] of Type I powders, compared to Type II powders, indicated that the specific surface area of Type I powders was lower. Type I powders were less elongated than Type II; measured elongation means were $0.18 \pm 0.02$ and $0.25 \pm 0.03$, respectively. The presence of crystalline lactose tomahawks/pyramids in Type II powders (Figure 1) likely contributed to the greater elongation observed. Surface free fat content did not vary significantly $(\mathrm{P}>0.05)$ between Type I $(0.96 \pm 0.30 \mathrm{~g}$ free fat $100 \mathrm{~g}^{-1}$ powder $)$ and Type II (0.81 $\pm 0.22 \mathrm{~g}$ free fat $100 \mathrm{~g}^{-1}$ powder $)$ powders. 
Table 2. Powder particle size and surface free fat for individual powders (mean of two replicates). Average values presented below were calculated based on powder type \pm standard deviation

\begin{tabular}{cccccc}
\hline $\begin{array}{c}\text { Powder } \\
\text { Type }\end{array}$ & $\begin{array}{c}\text { Powder } \\
\text { No. }\end{array}$ & $\begin{array}{c}\mathrm{D}[3,2] \\
(\mu \mathrm{m})\end{array}$ & $\begin{array}{c}\mathrm{D}(\mathrm{v}, 0.1) \\
(\mu \mathrm{m})\end{array}$ & $\begin{array}{c}\text { Span of } \\
\text { particles }\end{array}$ & $\begin{array}{c}\text { Surface free fat } \\
(\% \text { w/w of powder })\end{array}$ \\
\hline I & 1 & $183.0 \pm 6.0$ & $103.3 \pm 1.5$ & 1.5 & $1.5 \pm 0.0$ \\
I & 2 & $139.0 \pm 0.1$ & $77.4 \pm 0.1$ & 1.5 & $0.6 \pm 0.0$ \\
I & 3 & $166.2 \pm 0.1$ & $90.8 \pm 0.3$ & 1.6 & $1.1 \pm 0.0$ \\
I & 4 & $181.4 \pm 7.1$ & $129.0 \pm 3.8$ & 1.1 & $0.8 \pm 0.0$ \\
I & 5 & $170.0 \pm 0.1$ & $112.0 \pm 0.6$ & 1.3 & $1.0 \pm 0.0$ \\
I & 6 & $220.1 \pm 10.1$ & $140.5 \pm 6.93$ & 1.2 & $0.8 \pm 0.0$ \\
Average I & $\mathbf{1 7 6 . 5} \pm \mathbf{2 6 . 5}$ & $\mathbf{1 0 8 . 8} \pm \mathbf{2 3 . 5}$ & $\mathbf{1 . 4} \pm \mathbf{0 . 2}$ & $\mathbf{1 . 0} \pm \mathbf{0 . 3}$ \\
& & & & & \\
II & 7 & $160.0 \pm 7.5$ & $92.4 \pm 4.1$ & 1.6 & $0.9 \pm 0.0$ \\
II & 8 & $162.0 \pm 1.7$ & $100.9 \pm 2.1$ & 1.5 & $0.9 \pm 0.0$ \\
II & 9 & $117.0 \pm 0.1$ & $62.1 \pm 0.1$ & 1.8 & $0.4 \pm 0.0$ \\
II & 10 & $149.3 \pm 1.5$ & $87.6 \pm 0.7$ & 1.6 & $1.1 \pm 0.0$ \\
II & 11 & $143.0 \pm 1.4$ & $82.3 \pm 0.1$ & 1.6 & $0.8 \pm 0.0$ \\
II & 12 & $126.1 \pm 1.7$ & $68 \pm 0.8$ & 1.8 & $0.7 \pm 0.0$ \\
Average II & $\mathbf{1 4 2 . 9} \pm \mathbf{1 8 . 2}$ & $\mathbf{8 2 . 2} \pm \mathbf{1 4 . 8}$ & $\mathbf{1 . 7} \pm \mathbf{0 . 1}$ & $\mathbf{0 . 8} \pm \mathbf{0 . 2}$ \\
\hline
\end{tabular}

\subsection{Flowability}

Flowability of powders was measured by two means; a - Jenike flow index and b - the rate at which powder exited from a rotating drum. Table 3 summarises the flowability data. All powders measured had a flow index (i) of greater than 4 and, thus, were deemed to be easy flowing powders over the range of consolidating stresses applied [9]. There was no significant difference in flow index or drum flowability behaviour between Type I and II powders. Flow index and drum flowability were highly correlated for Type I powders ( $\mathrm{r}=$ $0.95)$ and somewhat correlated for Type II powders ( $r=0.69)$.

Type II powders had lower particle size $(\mathrm{P}<0.05)$, were less spherical $(\mathrm{P}<0.05)$ and were more elongated $(\mathrm{P}<0.05)$ compared to Type I powders. Taking this into account, it is perhaps surprising that average flowability of Type I and II powders was not significantly different (Table 3; P >> 0.05 for both flow index and drum flowability). Large particle size is generally desirable for good powder flowability [17]. Large powder particles reduce specific surface compared to smaller particles which reduces cohesive inter-particular interactions. In addition, increased spherocity of particles has been found to positively affect flowability [11]. However, particle size can often be weakly correlated with flowability [9] possibly due to the effect of surface composition, which also plays an important role in flowability [10]. Presence of crystalline lactose in Type II powders likely resulted in different overall surface composition compared to Type I powders. This difference could explain the good flow behaviour of Type II powders. Similarly, 
Yazdanpanah and Langrish [18] found that skim milk powder particles with crystalline surfaces and amorphous cores had better flowability than fully amorphous particles.

Table 3. Flowability of powders (mean of two replicates \pm standard deviation). Average values presented below were calculated based on powder type \pm standard deviation

\begin{tabular}{|c|c|c|c|}
\hline Powder Type & Powder No. & Flow index (i) & Drum flow $\left(\mathrm{g} \mathrm{min}^{-1}\right)$ \\
\hline $\mathrm{I}$ & 1 & $6.5 \pm 0.3$ & $32.9 \pm 1.0$ \\
\hline I & 2 & $4.6 \pm 0.3$ & $11.2 \pm 0.2$ \\
\hline I & 3 & $4.7 \pm 0.2$ & $17.4 \pm 1.7$ \\
\hline I & 4 & $7.7 \pm 0.8$ & $38.5 \pm 1.2$ \\
\hline I & 5 & $7.7 \pm 0.1$ & $38.5 \pm 1.5$ \\
\hline I & 6 & $8.7 \pm 0.5$ & $38.2 \pm 1.2$ \\
\hline \multicolumn{2}{|c|}{ Average I } & $6.6 \pm 1.6$ & $29.4 \pm 11.6$ \\
\hline II & 7 & $8.7 \pm 3.4$ & $39.0 \pm 0.3$ \\
\hline II & 8 & $8.3 \pm 0.1$ & $29.0 \pm 1.3$ \\
\hline II & 9 & $4.4 \pm 0.3$ & $24.8 \pm 0.1$ \\
\hline II & 10 & $6.9 \pm 0.3$ & $35.1 \pm 0.1$ \\
\hline II & 11 & $5.6 \pm 0.4$ & $34.6 \pm 1.0$ \\
\hline II & 12 & $4.7 \pm 0.2$ & $20.2 \pm 0.4$ \\
\hline \multicolumn{2}{|c|}{ Average II } & $6.4 \pm 2.1$ & $30.5 \pm 6.8$ \\
\hline
\end{tabular}

\subsection{Compressibility}

Compressibility was measured by two means a - difference in powder volume before and after tapping 100 times b - difference in volume before and after flow index analysis. No significant $(\mathrm{P}<0.05)$ difference in compressibility was observed between Type I and II powders. Compressibility measured during flow index testing was always higher than compressibility measured by tapping, indicating higher compressive force in the former measurement. Correlation between the two tests was high for Type I powders $(r=0.99)$ but for Type II powders no correlation was observed $(r=0.16)$. The exact reason why there was strong correlation for Type I powders and no correlation for Type II powders is unclear, but may be related to the presence of lactose crystals in Type II powders.

High compressibility of powders is often reported to be related to poor flowability $[11,16$, 19]. Table 4 shows correlations, for Type I and II powders, between all flowability and compressibility measurements. For Type I powders, compressibility was well correlated with flowability; $r$ was between -0.9 and -1 in each case. The negative sign of $r$ indicated that as compressibility increased, flowability decreased. For Type II powders, compressibility obtained by tapping was not correlated to flowability. Correlation of compressibility to flowability in Type II powders was higher when compressibility obtained from flow index was used. It is possible that, at the lower compression associated with the tapping test, lactose crystals present in Type II powders may have affected the established relationship between compressibility and flowability. It is clear from Table 5 that different methods which supposedly measure the same parameter i.e. compressibility, can be 
influenced by powder structure. Researchers must take into account powder structure when drawing conclusions from compressibility and flowability data.

Table 4. Correlation (Pearson's r) between compressibility and flowability measurements for Type I and II powders ( $n=6$ for each correlation)

\begin{tabular}{lcc|cc}
\hline & $\begin{array}{c}\text { Type I } \\
\text { flowability }\end{array}$ & $\begin{array}{c}\text { Flow } \\
\text { index }\end{array}$ & $\begin{array}{c}\text { Type II } \\
\text { Drum } \\
\text { flowability }\end{array}$ & $\begin{array}{c}\text { Flow } \\
\text { index }\end{array}$ \\
\hline Compressibility by tapping & -0.94 & -0.90 & 0.35 & 0.33 \\
Compressibility by flow index & -0.98 & -0.93 & -0.88 & -0.75 \\
\hline
\end{tabular}

\section{Conclusions}

Quick structural analysis of IMF powders using polarised light microscopy gave an indication of the process used for powder manufacture. The presence of large lactose tomahawk crystals in some IMF powders indicated a manufacturing process where at least some degree of dry blending of lactose was utilised. The presence of lactose crystals resulted in markedly different powder behaviour compared to similar powders containing no crystalline lactose. This highlights the importance of powder microstructural analysis to compliment more commonly used measurements of particle size, compressibility and flowability during analysis of powder behaviour.

\section{References}

[1] McCarthy, N.A.;Gee, V.L.;Hickey, D.K.;Kelly, A.L.;O'Mahony, J.A.;Fenelon, M.A., Effect of protein content on the physical stability and microstructure of a model infant formula. International Dairy Journal, 2013. 29,53-59.

[2] Mullane, N.R.;Whyte, P.;Wall, P.G.;Quinn, T.;Fanning, S., Application of pulsed-field gel electrophoresis to characterise and trace the prevalence of Enterobacter sakazakii in an infant formula processing facility. International Journal of Food Microbiology, 2007. 116,73-81.

[3] De Vilder, J.;Martens, R.;Naudts, M., Influence of process variables on some whole milk powder characterisitcs. Milchwissenschaft, 1976. 31(7),396-400.

[4] De Vilder, J.;Martens, R.;Naudts, M., The influence of dry matter content, the homogenisation and the heating of concentrate on the physical characteristics of whole milk powder. Milchwissenschaft, 1979. 34(2),78-84.

[5] McCarthy, N.A.;Kelly, A.L.;O'Mahony, J.A.;Hickey, D.K.;Chaurin, V.;Fenelon, M.A., Effect of protein content on emulsion stability of a model infant formula. International Dairy Journal, 2012. 25,80-86.

[6] Murphy, E.G.;Tobin, J.T.;Roos, Y.H.;Fenelon, M.A., A high-solids steam injection process for the manufacture of powdered infant milk formula. Dairy Science and Technology, 2013. 93,463-475. 
[7] Masters, K., Atomization, in Spray Drying In Practice. 2002, SprayDryConsult International ApS: Charlottenlund, Denmark. p. 129-179.

[8] Masters, K., Spray-air contact, particle formation and drying, in Spray Drying In Practice. 2002, SprayDryConsult International ApS: Charlottenlund, Denmark. p. 180215.

[9] Fitzpatrick, J.J.;Barringer, S.A.;Iqbal, T., Flow property measurement of food powders and sensitivity of Jenike's hopper design methodology to the measured values. Journal of Food Engineering, 2004. 61,399-405.

[10] Kim, E.H.J.;Chen, X.D.;Pearce, D., Effect of surface composition on the flowability of industrial spray-dried dairy powders. Colloids and Surfaces B: Biointerfaces, 2005. 46(3),182-187.

[11] Fu, X.;Huck, D.;Makein, L.;Armstrong, B.;Willen, U.;Freeman, T., Effect of particle shape and size on flow properties of lactose powders. Particuology, 2012. 10(2),203-208.

[12] Shaffer, K.;Paterson, A.H.J.;Davies, C.E.;Hebbink, G., Stokes shape factor for lactose crystals. Advanced Powder Technology, 2011. 22(4),454-457.

[13] Hanley, K.J.;Cronin, K.;O'Sullivan, C.;Fenelon, M.A.;O'Mahony, J.A.;Byrne, E.P., Effect of composition on the mechanical response of agglomerates of infant formulae. Journal of Food Engineering, 2011. 107,71-79.

[14] Murphy, E.G.;Tobin, J.T.;Roos, Y.H.;Fenelon, M.A., The effect of high velocity steam injection on the colloidal stability of concentrated emulsions for the manufacture of infant formulations. Procedia Food Science, 2011. 1,1309 - 1315.

[15] GEA-Niro. Analytical methods for dry milk products. 201228 Sept 2012]; Available from: www.niro.com/methods

[16] Crowley, S.V.;Gazi, I.;Kelly, A.L.;Huppertz, T.;O'Mahony, J.A., Influence of protein concentration on the physical characteristics and flow properties of milk protein concentrate powders. Journal of Food Engineering, 2014. 135,31-38.

[17] Schuck, P.;Dolivet, A.;Jeantet, R., Dehydration processes and powder properties, in Analytical Methods for Food and Dairy Powders. 2012, Wiley-Blackwell: West Sussex, UK. p. 1-43.

[18] Yazdanpanah, N.;Langrish, T.A.G., Egg-shell like structure in dried milk powders. Food Research International, 2011. 44(1),39-45.

[19] Schuck, P.;Dolivet, A.;Jeantet, R., Determination of flowability anf floodability indices, in Analytical Methods For Food and Dairy Powders. 2012, Wiley-Blackwell. p. 129-143. 